J. Dairy Sci. 95:5635-5644

http://dx.doi.org/10.3168/jds.2011-5106

(C) American Dairy Science Association ${ }^{\circledR}, 2012$.

\title{
Herd characteristics and cow-level factors associated with Prototheca mastitis on dairy farms in Ontario, Canada
}

\author{
L. Pieper, ${ }^{\star 1}$ A. Godkin,† U. Roesler,‡ A. Polleichtner,‡ D. Slavic,§ K. E. Leslie, ${ }^{\star}$ and D. F. Kelton* \\ *Department of Population Medicine, University of Guelph, Ontario, Canada, N1G 2W1 \\ †Veterinary Science and Policy Group, Ontario Ministry of Agriculture, Food and Rural Affairs (OMAFRA), Guelph, Ontario, Canada, N1G 4Y2 \\ łInstitute of Animal Hygiene and Environmental Health, Free University of Berlin, 10115 Berlin, Germany \\ §Animal Health Laboratory, University of Guelph, Ontario, Canada, N1G 6R8
}

\section{ABSTRACT}

Prototheca spp. are algae that cause incurable acute or chronic mastitis in dairy cows. The aim of this casecontrol study was the identification of cow- and herdlevel risk factors for this unusual mastitis pathogen. Aseptically collected composite milk samples from 2,428 milking cows in 23 case and 23 control herds were collected between January and May 2011. A questionnaire was administered to the producers, and cow-level production and demographic data were gathered. In 58 of 64 isolates, Prototheca spp. and Prototheca zopfii genotypes were differentiated using PCR and matrixassisted laser desorption/ionization time-of-flight mass spectrometry. All isolates were identified as Prototheca zopfii genotype 2 . The mean within-herd prevalence for Prototheca spp. was $5.1 \%$ (range $0.0-12.5 \%$ ). Case herds had a significantly lower herd-level prevalence of Staphylococcus aureus and a higher prevalence of yeasts than did control herds. The final logistic regression model for herd-level risk factors included use of intramammary injections of a non-intramammary drug [odds ratio $(\mathrm{OR})=136.8]$, the number of different injectable antibiotic products being used $(\mathrm{OR}=2.82)$, the use of any dry cow teat sealant (external OR $=80.0$; internal $\mathrm{OR}=34.2$ ), and having treated 3 or more displaced abomasums in the last $12 \mathrm{mo} \mathrm{OR}=44.7)$. The final logistic regression model for cow-level risk factors included second or greater lactation $(\mathrm{OR}=4.40)$ and the logarithm of the lactation-average somatic cell count $(\mathrm{OR}=2.99)$. Unsanitary or repeated intramammary infusions, antibiotic treatment, and off-label use of injectable drugs in the udder might promote Prototheca udder infection.

Key words: dairy cow, mastitis, Prototheca, casecontrol study

Received October 28, 2011.

Accepted June 15, 2012.

${ }^{1}$ Corresponding author: pieperl@uoguelph.ca

\section{INTRODUCTION}

Prototheca is a colorless, unicellular algae that can cause granulomatous mastitis in dairy cows. Prototheca spp. have been isolated from cases of clinical and subclinical mastitis in several countries, including Canada (Dion, 1982), the United States (Pore et al., 1987; Anderson and Walker, 1988; Jordan et al., 2003), Brazil (Costa et al., 1996; Corbellini et al., 2001; Bueno et al., 2006), Germany (Baumgärtner, 1997; Rösler and Hensel, 2003; Tenhagen et al., 2005; Möller et al., 2007), and Japan (Osumi et al., 2008).

Prototheca spp. consists of Prototheca wickerhamii, Prototheca stagnora, Prototheca ulmea, Prototheca zopfii, Prototheca blaschkeae (Rösler et al., 2006), and Prototheca cutis sp. nov. (Satoh et al., 2010). Prototheca zopfii genotype 2 (Möller et al., 2007; Aouay et al., 2008; Marques et al., 2008) and P. blaschkeae (Aouay et al., 2008; Marques et al., 2008) have both been identified as causing clinical and subclinical mastitis. Prototheca zopfii genotype 1 has induced subclinical mastitis in challenge trials (Roth, 2009; Ito et al., 2011) but is generally not associated with naturally occurring mastitis. Of the rarely occurring cases of human protothecosis, a few have been associated with $P$. zopfii and P. blaschkeae (Rösler et al., 2006; Lass-Flörl and Mayr, 2007; Zhang et al., 2010), suggesting a zoonotic potential of bovine disease due to those Prototheca species.

Different Prototheca species have been found in the dairy farm environment, usually in moist areas containing organic matter, such as mud (Anderson and Walker, 1988), spoiled feed stored in silos (Baumgärtner, 1997), leftover feed in mangers (Anderson and Walker, 1988), and dirty water troughs (Anderson and Walker, 1988; Costa et al., 1997). Additionally, they have been identified in feces of cows (Anderson and Walker, 1988; Enders and Weber, 1993; Costa et al., 1997), calves (Costa et al., 1997), sows (Pore and Shahan, 1988), sheep (Pore and Shahan, 1988), and rodents (Pore and Shahan, 1988). However, the isolation of Prototheca from the dairy herd environment seems to be independent from previous Prototheca isolation from mastitis 
samples in the same herd (Blaschke-Hellmessen and Schuster, 1984; Anderson and Walker, 1988).

The prevalence of Prototheca spp. in routine milk samples is very low ( $0.1 \%$ of submitted samples) (Wilson et al., 1997). However, the prevalence of cows with Prototheca mastitis could reach more than $30 \%$ of the lactating herd during a Prototheca outbreak (Costa et al., 1997; Dubravka et al., 2006).

Because no treatment has yet been found to cure Prototheca mastitis in vivo (Anderson and Walker, 1988; Lagneau, 1996; Jánosi et al., 2001), emphasis should be placed on identifying risk factors and implementing prevention strategies on affected dairy farms. The aim of this case-control study was to identify risk factors associated with Prototheca mastitis on dairy farms in Ontario, Canada.

\section{MATERIALS AND METHODS}

\section{Data Collection}

For this case-control study, 23 herds with repeated (2 or more) Prototheca-positive milk culture results from mastitis samples within the last $2 \mathrm{yr}$ were selected by Ontario veterinarians. For selection of the control herds, the veterinarians named 4 suitable herds that could serve as controls. These farms needed to be similar to the respective case herds in the number of cows and stall type for milking cows, but with no history of Prototheca mastitis within the last 2 yr. Out of these 4 herds, the investigators randomly picked a control herd by drawing a herd name from a hat. The farms were included in the study if they were enrolled in milk recording through CanWest DHI (Guelph, ON, Canada). For 1 case-control pair, 2 additional control herds had to be sampled because the first and second herds originally enrolled as controls were found to have Prototheca-positive milk samples and a history of Prototheca mastitis from more than $2 \mathrm{yr}$ ago. All statistical analyses were performed without these 2 "false" control herds.

Between January 2011 and May 2011, the selected case and control herds were visited once during milking time by the researchers, the herd veterinarian, or a veterinary technician for aseptic collection of composite milk samples from each lactating cow. Dry cows were not sampled. Milk samples were taken after the usual premilking udder preparation by the farmer or milking staff, and before attachment of the milking unit. The teat ends were cleaned with an alcohol swab, the first few strips of milk were discarded, and a sample from all milking quarters was collected into one vial per cow. A clinical examination of the cows was not performed. Milk samples were submitted to the Animal Health
Laboratory (University of Guelph, Ontario, Canada) for identification of Prototheca spp. and other mastitis pathogens. Ten microliters of each milk sample was plated on sheep blood agar plates (Oxoid Ltd., Basingstoke, UK) using a calibrated loop (Thermo Fisher Scientific Inc., Waltham, MA) and incubated at $35^{\circ} \mathrm{C}$ $\pm 2^{\circ} \mathrm{C}$ for $48 \mathrm{~h}$. Prototheca spp. were identified using colony morphology and Gram stain. Other mastitis pathogens were identified using colony morphology, Gram stain, and biochemical pattern according to National Mastitis Council guidelines (Hogan et al., 1999). The laboratory personnel were blinded to case or control status of the sampled herds. A random subset of 58 Prototheca isolates was shipped in slant agar tubes (Bio-Media Unlimited Ltd., Woodbridge, ON, Canada) to the Institute of Animal Hygiene and Environmental Health, Free University of Berlin (Berlin, Germany), for further species and genotype differentiation using PCR and matrix-assisted laser desorption/ionization time-of-flight mass spectrometry (MALDI-TOF MS; Bruker Daltonics, Bremen, Germany) with methods described previously (Rösler et al., 2006; von Bergen et al., 2009; Murugaiyan et al., 2012).

A questionnaire developed and pretested by the research team was administered via interview. The questionnaire contained 54 short questions about herd characteristics, management, and medication practices (Table 1). Further herd- and cow-level information was gathered using DHI records (Tables 1 and 2).

\section{Statistical Analysis}

Statistical analyses were conducted using the statistical software package STATA 10.1 (StataCorp, College Station, TX). For each herd and each mastitis pathogen, the within-herd prevalence was calculated by adding up the number of isolates divided by the number of milk samples. The within-herd prevalence in case and control farms was compared using the Mann-Whitney U test. The following variables were created with information from the original questionnaire responses: changed dry cow treatment within the last 3 yr (yes/ no), number of different intramammary antibiotic mastitis treatment products (NrIntramam), number of different injectable antibiotic treatment products (NrInjectable; both continuous), and use of injectable sulfonamides (yes/no). The questionnaire data were screened for differences between case and control farms using descriptive statistics, univariable logistic regression for categorical variables, and the Mann-Whitney $\mathrm{U}$ test for continuous variables. Variables identified as risk factors $(P<0.1)$ were tested for collinearity using the Spearman rank correlation $(\boldsymbol{\rho})$. High correlations $(\rho>0.6)$ were found between use of Spectramast LC 
Table 1. Descriptions and levels of risk factors for herd-level analyses (information gathered from questionnaire unless otherwise specified)

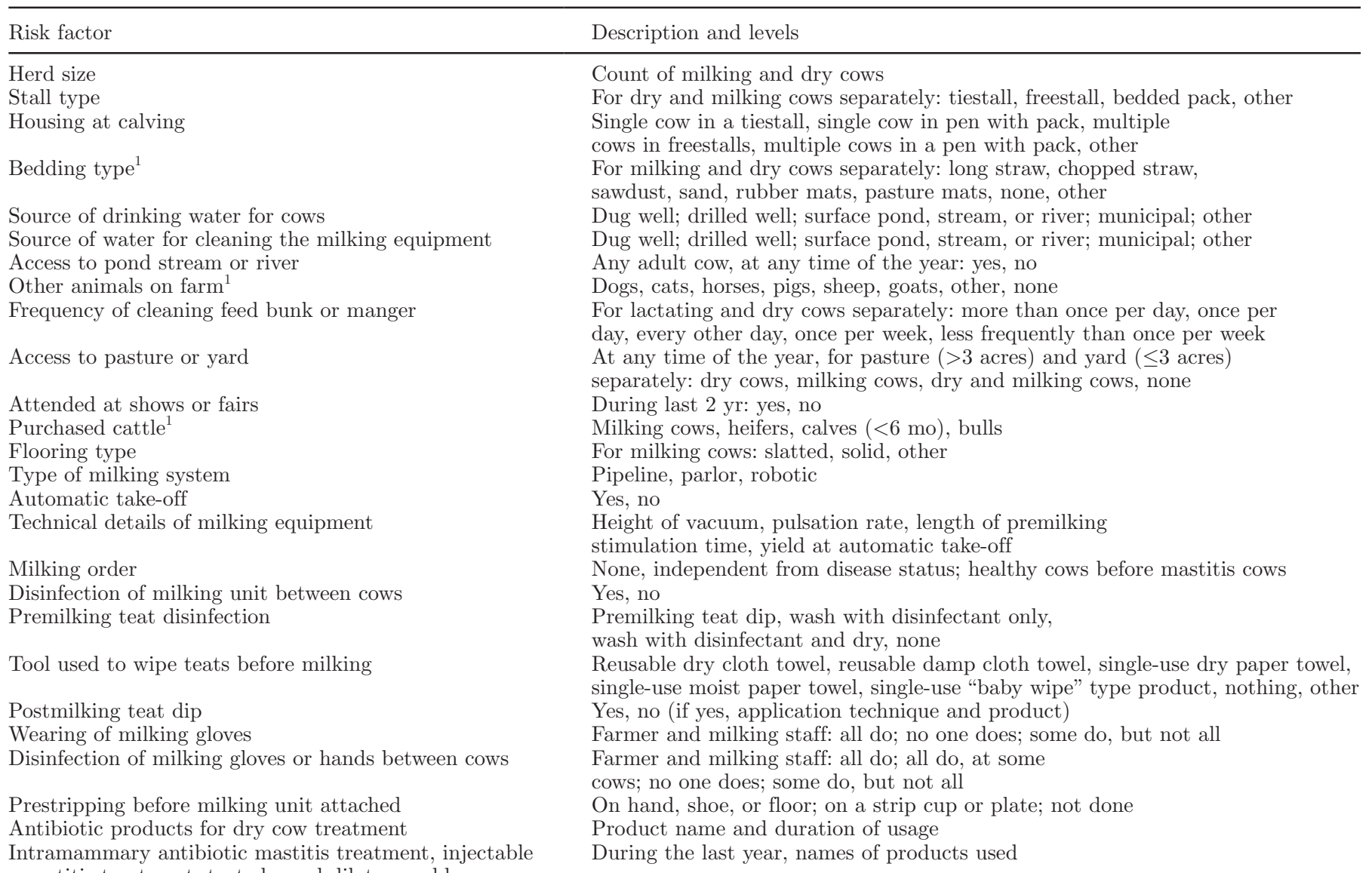

mastitis treatment, teat channel dilators, udder creams or balms

Teat sealant

Teat surgeries

Off-label drug use in the udder (ImINID)

Number of cows with treatments

Bacterial count, ${ }^{2} \times 1,000 \mathrm{cfu} / \mathrm{mL}$

Milk yield, ${ }^{3} \mathrm{~kg}$

Milk components, ${ }^{3} \mathrm{~kg}$

$\mathrm{SCC},{ }^{2,3} \times 1,000$ cells $/ \mathrm{mL}$

Internal, external, none (if used, product and duration of usage)

During the last 2 yr: yes, no

Yes, no (if yes, product name)

During last year, for ketosis, displaced abomasum, mastitis, and lameness

Over 12 mo, average monthly bulk tank bacterial count

Over 12 mo, average monthly milk yield per day and 305-d lactation

Over $12 \mathrm{mo}$, average monthly milk fat and milk

protein per day and 305-d lactation

Over 12 mo, average monthly bulk tank SCC and weighted cow SCC

${ }^{1}$ Multiple answers possible.
${ }^{2}$ From Dairy Farmers of Ontario (DFO), Mississauga, ON, Canada
${ }^{3}$ From CanWest DHI (Guelph, ON, Canada) records.

(Pfizer Animal Health, Pfizer Canada Inc., Kirkland, QC, Canada) as a lactating cow mastitis treatment and NrIntramam $(\rho=0.65)$ and between use of sulfon- amides and NrInjectable $(\rho=0.61)$. The more general and biologically plausible variables NrIntramam and NrInjectable were tested first in the model.

Table 2. Description of risk factors for cow-level analyses from DHI records

\begin{tabular}{ll}
\hline Risk factor & Description \\
\hline Lactation number & Current lactation number \\
Milk yield, $\mathrm{kg}$ & Milk production from last herd test-day and estimated over $305 \mathrm{~d}$ \\
Milk components, $\mathrm{kg}$ & Milk fat and protein production from last herd test-day and estimated over 305 d \\
$\mathrm{SCC}, \times 1,000$ cells $/ \mathrm{mL}$ & SCC from last herd test-day and estimated over 305 d \\
Previous lactation number & Lactation number in previous lactation \\
Previous lactation-average SCC $, \times 1,000$ cells $/ \mathrm{mL}$ & SCC in previous lactation \\
Pedigree & Cow's dam and sire identification number \\
\hline
\end{tabular}


Manual forward selection using a $P$-value of 0.05 was chosen for logistic regression model building. Only biologically meaningful interactions were tested in the model. An interaction between NrInjectable and the intramammary injection of a non-intramammary drug (ImINID) was not significant $(P=0.64)$. Linearity was assessed for continuous variables and in the case of a nonlinear relationship between the predictor and outcome variable, the predictor variable was either transformed or categorized. The Hosmer-Lemeshow goodness-of-fit test was used to assess the model fit (5 groups, $P=0.36$ ). By plotting raw residuals, standardized residuals, leverage, and delta-beta (influence of the specific covariate pattern on model)against the predicted outcome, covariate patterns that fit poorly in the model or that had a great influence on the model were visually identified. One covariate pattern was identified as very influential because of a high number of observations.

The model-building process described previously was repeated for the cow-level risk factors in case farms. Control farms were not included in these analyses, as the cows, by default, do not have a probability of having a Prototheca-positive laboratory result. Logarithmic transformation was performed on all SCC variables before the analyses. Risk factors were compared among cows with Prototheca-positive, culture-negative, and other mastitis pathogen-positive laboratory results using the Kruskal-Wallis rank sum test, and for post hoc comparisons, the Mann-Whitney U test. High correlations were found between lactation number and cow age in days $(\rho=0.93)$, and test-day SCC and lactation-average SCC $(\rho=0.80)$. Lactation number and lactation average SCC were, as the more informative variables, tested in the model. Cows with mastitis pathogens other than Prototheca spp. were excluded from the final model for cow-level risk factors. An interaction term between age category and lactation-average SCC was not significant in the model $(P=0.71)$. The model fit was assessed using the Hosmer-Lemeshow goodness-of-fit test ( 5 groups, $P=0.21$ ). Five covariate patterns showed high Pearson residuals and high standardized residuals. Four were single observations of Prototheca-positive, first-lactation heifers with lactation-average SCC of 240,000 to 962,000 cells $/ \mathrm{mL}$. One covariate pattern consisted of 7 observations of first-lactation heifers with a lactation-average SCC of $<50,000$ cells $/ \mathrm{mL}$, whereas 1 of them had a Protothecapositive laboratory result. Only those 5 first-lactation heifers had Prototheca-positive laboratory results.

A random effects model accounting for clustering by herd was tested. It was not significantly different from the more parsimonious logistic regression model without random effects (likelihood ratio test; $P=0.11$ ).
Therefore, the ordinary logistic regression model is shown in the results. A probability of $P<0.05$ was considered significant in all analyses.

\section{RESULTS}

All cows in this study were Holstein-Friesian dairy cows. The mean number of cows in case and control herds was 66.9 (SD: 33.3) and 61.5 (SD: 20.3), respectively. According to the CanWest DHI Progress Report for Ontario (CanWest, 2009), 82.3\% of Ontario dairy herds keep from 1 to 99 cows. However, the mean number of cows in the study herds was lower than the average number of cows per herd based on that report. The 305-d milk production per cow in the study farms was lower than the average 305-d milk production of Holstein-Friesian cows in Ontario. Furthermore, the smaller size of the study herds was represented in the higher percentage of tiestalls compared with the average percentage of tiestalls in DHI dairy herds (Table 3 ). Case and control herds did not differ significantly in 305-d or test-day milk yield, fat yield, or protein yield per cow over the last 12 mo before sampling. Over the same period, case herds tended to have higher SCC $(P$ $=0.06)$ and bacterial counts $(P=0.06)$ in the bulk tank milk compared with control herds. We found no difference in the number of times the producer exceeded the limits of 500,000 cells $/ \mathrm{mL}(P=0.23)$ or $50,000 \mathrm{cfu} /$ $\mathrm{mL}(P=0.64)$ in bulk tank samples. The weighted average SCC over the last 12 mo before herd sampling were higher $(P=0.04)$ in case than in control herds.

Overall, 2,428 milk samples were cultured: 1,229 from case farms and 1,199 from control farms. Culturenegative results were obtained from $83.0 \%$ of all milk samples, and $0.62 \%$ of samples were contaminated. Significant differences in within-herd prevalence between case and control herds were found for Prototheca spp., Staphylococcus aureus, and yeasts (Table 4). Prototheca spp. were isolated from 64 milk samples from 18 different herds. The within-herd prevalence of Prototheca spp. in case herds ranged from $0.0 \%$ to $12.5 \%$ of sampled cows, with an average of $5.1 \%$. In 5 case farms, no Prototheca spp. were isolated. The average within-herd prevalence for Staph. aureus in case herds was less than half that in control herds. Yeasts, Corynebacterium bovis, Enterobacter cloacae, Klebsiella spp., Escherichia coli, Proteus spp., and Enterococcus spp. were only isolated from case herd samples, whereas Streptococcus agalactiae were only isolated from samples from 1 control herd. Prototheca spp. were isolated together with Staph. aureus in 4 samples. Other combinations of pathogens were not observed. Using PCR and MALDITOF MS, all analyzed isolates were identified as Prototheca zopfii genotype 2 . The isolates were similar to 
Table 3. Demographic characteristics of case and control farms

\begin{tabular}{|c|c|c|c|}
\hline Parameter & Case & Control & $\mathrm{DHI}^{1}$ \\
\hline 305-d Milk production per cow, kg (SD) & $9,304(1,806.9)$ & $9,271(1,607.8)$ & 9,650 \\
\hline \multicolumn{4}{|l|}{ Stall type for milking cows, no. (\%) } \\
\hline Freestall & $3(13.0)$ & $2(8.7)$ & 26.5 \\
\hline
\end{tabular}

${ }^{1}$ CanWest DHI (2009).

the type and reference strains SAG $2021^{\mathrm{T}}$, RZ II-2, and RZ II-3 (Culture Collection of the Institute of Animal Hygiene and Environmental Health, Free University of Berlin, Germany) that were previously isolated from clinical bovine mastitis in Germany.

Significant differences between case and control farms, based on univariable analysis of the questionnaire sections, are presented in Table 5. The use of an internal dry cow teat sealant was identified as a risk factor for being a case herd [odds ratio $(\mathbf{O R})=5.00, P=0.033$ ]. OrbeSeal (bismuth subnitrate, Pfizer Animal Health) was the only internal teat sealant used on the study farms. Most commonly, antibiotic dry cow treatment was administered to all cows at the end of lactation. On 1 case and 1 control farm, only multiparous cows were treated, and on 4 control farms, cows only received dry treatment based on herd-specific conditions (e.g., high SCC). Interestingly, ImINID was identified as the strongest risk factor $(\mathrm{OR}=9.6, P=0.003)$. For this procedure, the producers most commonly used Predef 2x (isuflupredone acetate, Pfizer Animal Health; 5 producers), penicillin (Durvet Inc., Blue Springs, MO; 5 producers), or Excenel RTU (ceftiofur hydrochloride,
Pfizer Animal Health; 3 producers) as off-label intramammary infusions.

Table 6 shows the mean number of different antibiotics used, as well as the mean frequency of disease treatments in case and control farms. Case farms used a significantly higher NrIntramam. Even though not statistically significant, the data suggest that case farms may also use a higher NrInjectable $(P=0.06)$. The frequencies of treatments were similar between case and control farms for the most common diseases, with exception of abomasal displacement. Case farms tended to have treated more abomasal displacements during the past 12 -mo period $(P=0.051)$ than control farms.

We observed no differences in other analyzed risk factors between case and control farms. The final model for herd-level risk factors included ImINID (OR $=136.8)$, NrInjectable $(\mathrm{OR}=2.82)$, the use of any dry cow teat sealant (external OR $=80.0$; internal $\mathrm{OR}=34.2$ ), and having treated 3 or more displaced abomasums in the last 12 mo $(\geq \mathbf{3 D A} ; \mathrm{OR}=44.7$; Table 7$)$.

For case farms, DHI data were available for 1,174 of 1,229 sampled cows (95.5\%). In case farms, cows with Prototheca-positive laboratory results were significantly

Table 4. Mean, SD, minimum, and maximum within-herd prevalence (\%) of isolated pathogens (number of isolates/number of cows sampled) in case and control herds

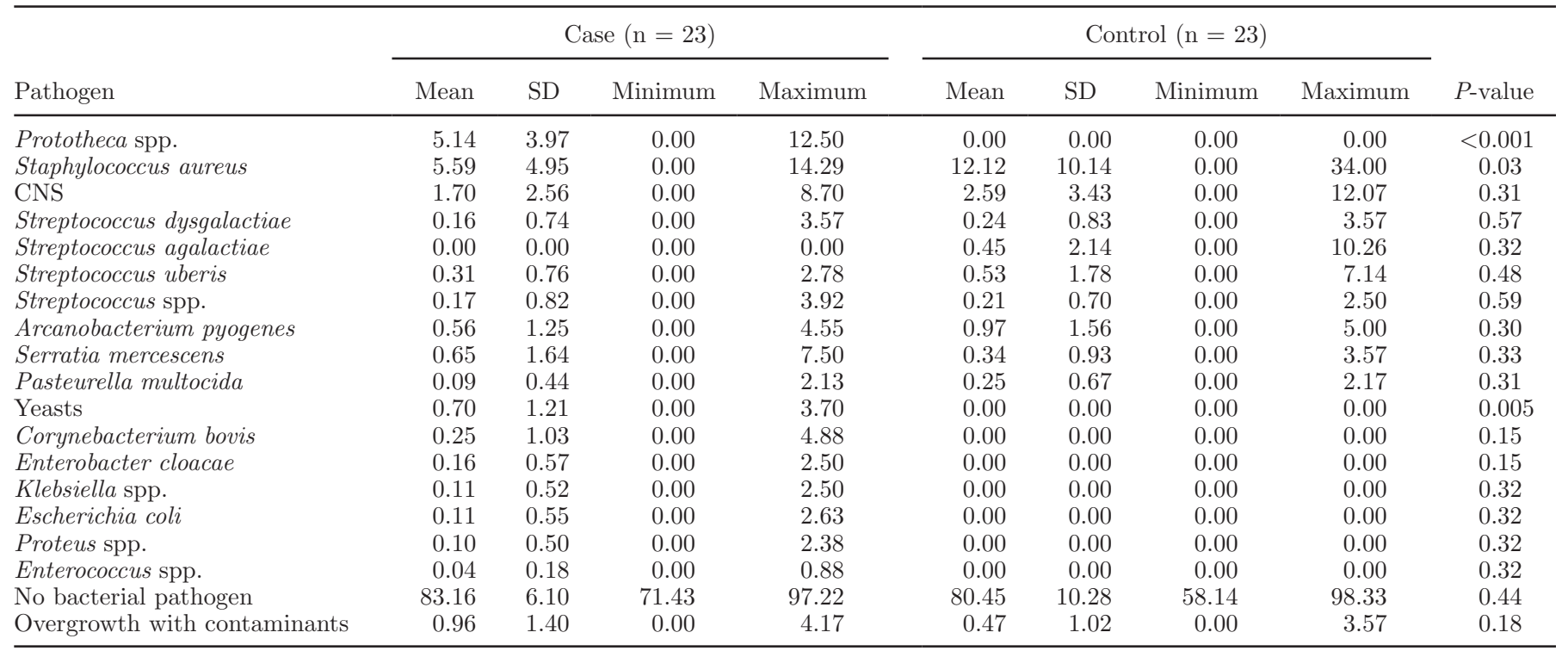


Table 5. Univariable analysis of significant farm-level risk factors for being a case farm

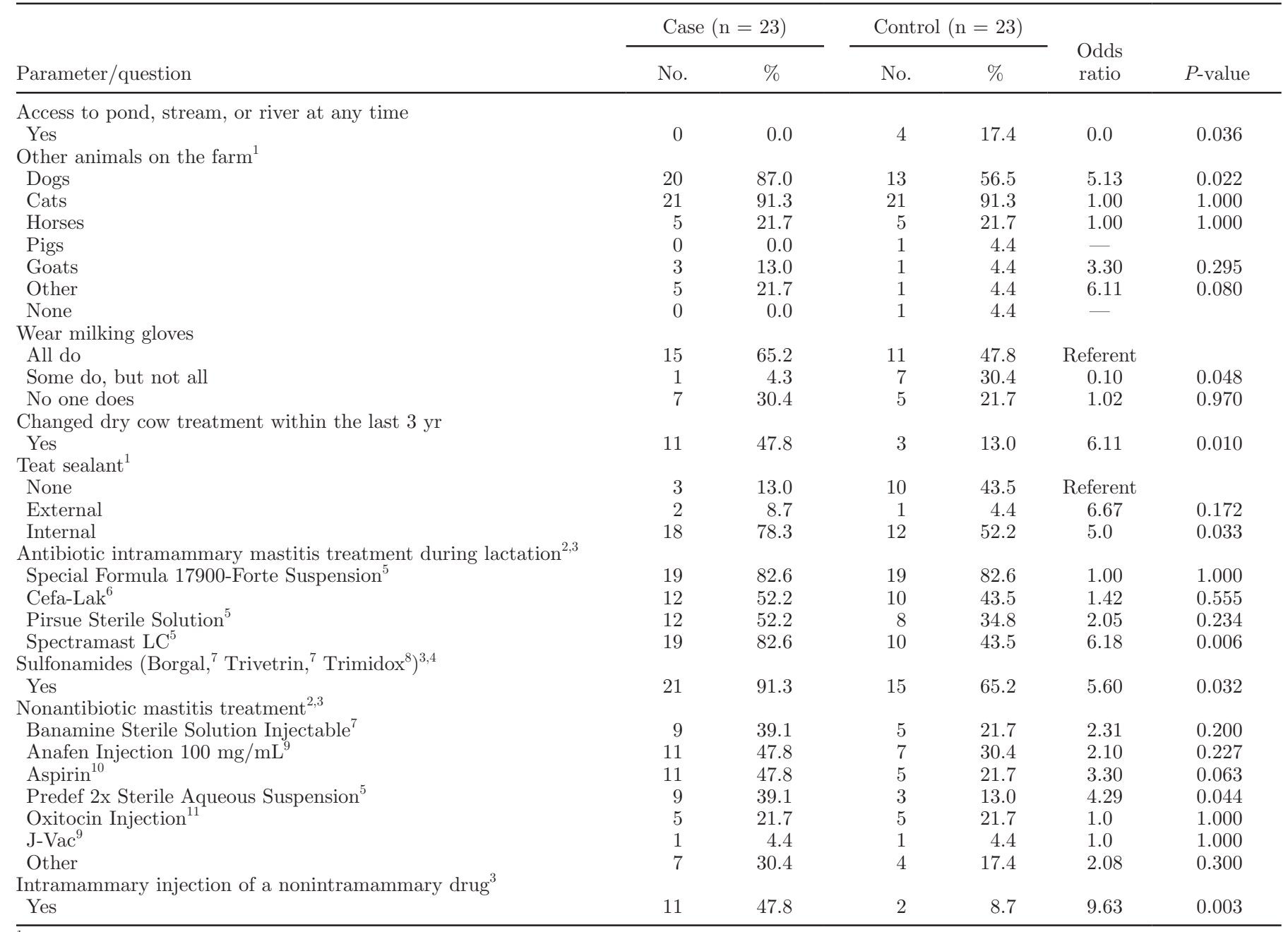

${ }^{1}$ Use of any teat sealant.

${ }^{2}$ Multiple answers possible.

${ }^{3}$ During the last $24 \mathrm{mo}$.

${ }^{4}$ Sulfonamides $=$ use of any injectable sulfonamide.

${ }^{5}$ Pfizer Animal Health, Pfizer Canada Inc. (Kirkland, QC, Canada).

${ }^{6}$ Boehringer Ingelheim (Canada) Ltd. (Burlington, ON, Canada).

${ }^{7}$ Intervet/Schering-Plough Animal Health, Intervet Canada Corp. (Kirkland, QC, Canada).

${ }^{8}$ Vétoquinol Canada Inc. (Lavaltrie, QC, Canada).

${ }^{9}$ Merial Canada, Inc. (Baie d'Urfé, QC, Canada).

${ }^{10}$ Different manufacturers.

${ }^{11}$ Bimeda-MTC Animal Health Inc. (Lavaltrie, QC, Canada).

Table 6. Mean (SD) of number of different antibiotics used during the last 24 mo and of number of disease treatments in the last $12 \mathrm{mo}$ in case and control farms

\begin{tabular}{|c|c|c|c|}
\hline Parameter & Case $(\mathrm{n}=23)$ & Control $(\mathrm{n}=23)$ & $P$-value \\
\hline Number of different intramammary antibiotics ${ }^{1}$ & $2.70(0.93)$ & $2.04(0.88)$ & 0.018 \\
\hline Number of different injectable antibiotics ${ }^{1}$ & $1.96(1.19)$ & $1.35(1.07)$ & 0.060 \\
\hline Ketosis $^{2}$ & $9.00(6.65)$ & $8.04(6.54)$ & 0.565 \\
\hline Abomasal displacements ${ }^{2}$ & $4.17(4.26)$ & $2.96(1.52)$ & 0.051 \\
\hline Mastitis $^{2}$ & $15.41(14.92)$ & $13.91(16.38)$ & 0.239 \\
\hline Lameness $^{2}$ & $7.83(9.17)$ & $7.91(6.84)$ & 0.493 \\
\hline
\end{tabular}

${ }^{1}$ During the last $24 \mathrm{mo}$.

${ }^{2}$ During the last $12 \mathrm{mo}$. 
Table 7. Odds ratio (OR), 95\% CI, and significance level of the final logistic regression model for herd-level risk factors for being a case herd

\begin{tabular}{lccc}
\hline Parameter $^{1}$ & OR & $95 \%$ CI & $P$-value \\
\hline ImINID & 136.8 & $5.40 ; 3,463.74$ & 0.003 \\
NrInjectable & 2.82 & $1.043 ; 7.653$ & 0.041 \\
Teat sealant & & & \\
None & Referent & $-\overline{-}$ & - \\
External & 80.0 & $1.11 ; 5,765.89$ & 0.045 \\
Internal & 34.2 & $2.22 ; 526.75$ & 0.011 \\
$\geq 3$ DA & 41.1 & $2.69 ; 628.34$ & 0.008 \\
\hline
\end{tabular}

${ }^{1}$ ImINID = intramammary injection of a nonintramammary drug; NrInjectable $=$ number of different injectable antibiotic products; Teat sealant $=$ use of any teat sealant; $\geq 3 \mathrm{DA}=$ having treated 3 or more displaced abomasums in the last 12 mo.

older than cows with culture-negative results or cows with other mastitis pathogens (Table 8). Cows that tested positive or negative for Prototheca did not differ in stage of lactation or test-day milk, fat, or protein yields. Cows that were culture positive for Prototheca spp. or other mastitis pathogens had higher test-day SCC and lactation-average SCC than culture-negative cows. Four Prototheca-positive cows had test-day SCC $<100,000$ cells/mL, and 1 Prototheca-positive cow had a lactation-average SCC $<100,000$ cells $/ \mathrm{mL}$. Using the pedigree information from DHI, no mother-daughter pair could be detected among the Prototheca-positive cows in this study, and cows with Prototheca-positive laboratory results were offspring of many different sires. The final model for the cow-level risk factors (Table 9) indicates higher odds of having a laboratory result positive for Prototheca in multiparous cows and in those with high lactation-average SCC.

\section{DISCUSSION}

This case-control study was conducted to identify herd- and cow-level risk factors for Prototheca mastitis. Laboratory, production, and questionnaire data were compared for 23 case-control pairs of herds. Multivariable logistic regression models were utilized to predict the probability of being either a case farm or a Prototheca-positive cow in a case farm.

Case and control farms were similar to each other in basic demographic parameters. Furthermore, because $82.3 \%$ of Ontario dairy farms have a herd size of $<100$ cows, the studied farms can be considered representative of the majority of Ontario dairy farms in terms of herd size. Both case and control farms had a lower milk production per cow than average DHI farms, which might be associated with the smaller average herd size of the study farms.

A Prototheca spp. herd-level prevalence of $5.1 \%$ from our study is similar to that described in the literature for

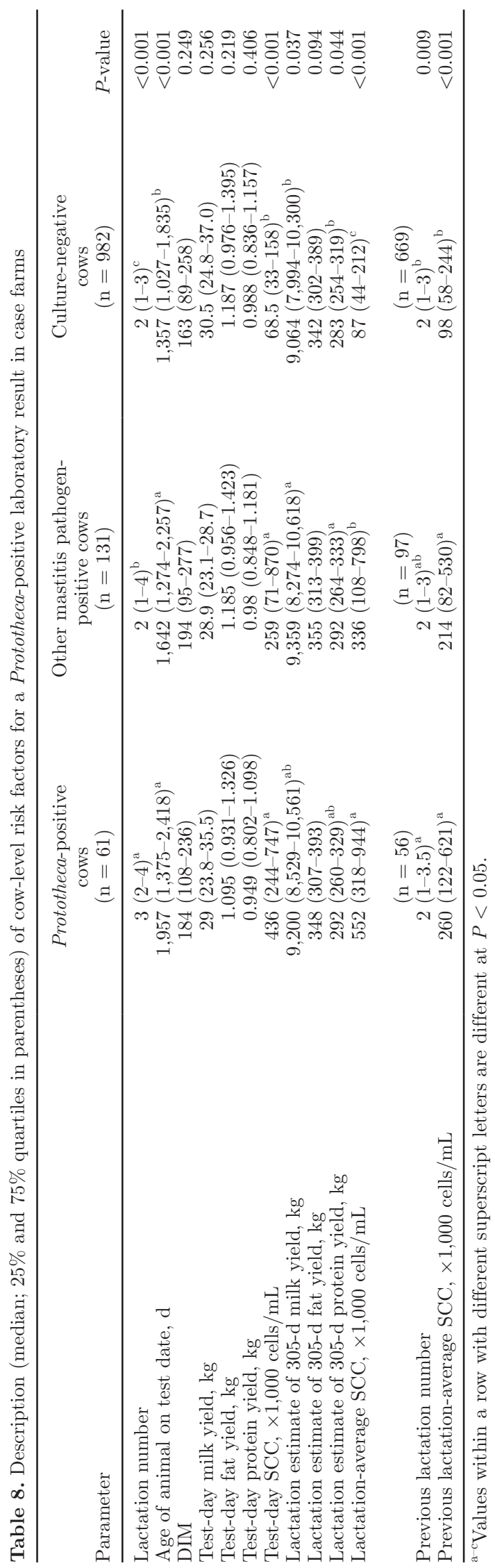

Journal of Dairy Science Vol. 95 No. 10, 2012 
Table 9. Odds ratio (OR), 95\% CI, and significance level of the final logistic regression model for cow-level risk factors for Prototheca-positive laboratory results versus a culture-negative result (other mastitis pathogens excluded) in case farms

\begin{tabular}{llcr}
\hline Parameter & OR & $95 \%$ CI & $P$-value \\
\hline Second lactation or greater & 4.40 & $1.697 ; 11.399$ & 0.002 \\
Log-transformed lactation-average SCC & 2.99 & $2.295 ; 3.896$ & $<0.001$ \\
\hline
\end{tabular}

herds with endemic Prototheca mastitis (Baumgärtner, 1997; Bueno et al., 2006). Among those isolates that were further investigated, only Prototheca zopfii genotype 2 was identified. This supports the predominant role of Prototheca zopfii genotype 2 in the pathogenesis of bovine mastitis caused by Prototheca spp. (Ahrholdt and Roesler, 2011).

Five case farms did not yield Prototheca-positive milk culture results. However, we decided to include those farms as cases because they met the predefined case definition, based on a history of repeated Prototheca spp. mastitis cases within the last 2 yr. In this study, where the herds were only cultured once using composite milk samples, it is very likely to see one or more false-negative culture results based on the imperfect sensitivity of the test and the intermittent shedding of the organism. Furthermore, in small herds, such as those in Ontario, where very few cows are positive for Prototheca spp. at a given time, it is also likely that a Prototheca-infected cow had been culled for mastitis or other reasons in the period preceding the sampling day, and would therefore not appear in the culture results. Finally, because only lactating cows were sampled, Prototheca-positive cows that were dry at the time of the herd visit would not have been tested. In combination, all of these factors might have decreased the herdand cow-level sensitivity of the culture results, and it is likely that the true prevalence of positive herds and cows was higher than detected in this study.

The mean within-herd prevalence of Staphylococcus aureus was considerably lower in case herds than in control herds. It might be that the veterinarians who selected the farms were biased in their choice and selected controls with poor performance in terms of udder health. This might have influenced the risk factor analyses and biased the estimates toward the null.

Several case reports about herds with outbreaks of Prototheca mastitis have described poor milking hygiene (lack of one or more of the following: prestripping, cleaning the udder prior to milking, disinfection of milking unit between cows, or postmilking teat dip) and wet, dirty, and muddy outdoor areas on those farms (Costa et al., 1996; Baumgärtner, 1997; Corbellini et al., 2001; Bueno et al., 2006). This case-control study is the first large-scale study that assessed farm-level risk factors objectively. Surprisingly, we did not find that specific farm characteristics, specific farm management, or milking hygiene deficiencies were risk factors for Prototheca mastitis on the case farms.

Baumgärtner (1997) and Hodges et al. (1985) reported problems with the milking equipment in farms where Prototheca outbreaks occurred. Most of the producers in this study were unable to provide the precise technical data for milking equipment function on their farm. Therefore, an association between milking equipment performance and Prototheca mastitis, if present, could not be detected in this study because of lack of appropriate data.

Other risk factors that have been mentioned in the literature were the extensive use of antibiotics, change of dry cow treatment, and unsanitary udder injections (Spalton, 1985; Corbellini et al., 2001; Jánosi et al., 2001). In the current study, we found that variables associated with intramammary treatment (internal teat sealant, ImINID) and NrInjectable were farm-level risk factors for Prototheca mastitis. As in any case-control study, this association alone does not conclusively prove a cause-effect relationship. Producers might have implemented these practices in an effort to control Prototheca mastitis in their herds. It remains unclear whether Prototheca-positive cows were treated with these drugs, because treatment records for individual cows were not available. However, considering that yeasts were only found on case farms, this likely suggests that Prototheca is, like yeast, an opportunistic pathogen. Furthermore, unsanitary udder injections might have introduced Prototheca spp. into the udder. Baumgärtner (1997) presumed that Prototheca infections are promoted by high infection pressure on affected farms together with antibiotic treatments that inhibited the competitive natural udder flora.

The final logistic regression model for farm-level risk factors included the variable $\geq 3 \mathrm{DA}$. To our knowledge, an association between displaced abomasum and mastitis caused by Prototheca has not been previously reported. A high number of displaced abomasums can be caused by factors such as poor ration formulation, poor feed hygiene and quality, or inadequate feed bunk management, all of which might be indicators of overall farm management and cleanliness.

Similar to the present study, Tenhagen et al. (1999) found that higher lactation number was a risk factor for 
Prototheca mastitis. On the other hand, $25 \%$ of their Prototheca-positive cows were primiparous, whereas in our study, only $8.2 \%$ of affected cows were primiparous. The same study by Tenhagen et al. (1999) reported higher SCC during lactation in cows that were later affected by Prototheca mastitis. Those authors suspected that the disrupted integrity of the udder tissue acted as a Prototheca mastitis-promoting factor.

The logistic regression model for cow-level risk factors suggested that culturing milk samples for Prototheca spp. from multiparous cows and those with high SCC might be an efficient way to screen for infected cows in farms where Prototheca spp. has been confirmed previously. Nevertheless, we found several culture-positive cows with test-day SCC $<100,000$ cells $/ \mathrm{mL}$ and some primiparous cows with Prototheca-positive laboratory results. It might be that those cows with low SCC became infected shortly after the DHI test day, or that a high SCC from the affected quarter was diluted in the composite DHI test sample due to agalactia caused by the Prototheca mastitis. On the other hand, SCC $<100,000$ cells/mL in cows with Prototheca zopfii infection have been reported in quarter and composite milk samples (Tenhagen et al., 2005; Bueno et al., 2006). As suggested (Rösler and Hensel, 2003; Bueno et al., 2006), eradication attempts should use repeated testing of the whole herd rather than testing only high-risk cows. Testing only the high-risk animals for Prototheca spp. might miss infected animals that could later perpetuate the infection in the herd. Furthermore, in the present study, composite milk samples, instead of quarter milk samples, were used for milk culture. This might have decreased the sensitivity of the laboratory culture results (Baumgärtner, 1997; Tenhagen et al., 2005) and biased the estimates of the cow-level parameters toward the null. It may be that Prototheca mastitis eradication attempts should use quarter milk samples.

The current work was a preliminary investigation. The sample size might have been too small and the data collection methods too general to detect differences in milking hygiene and farm management practices. The wide confidence intervals in the final herd-level model indicate uncertainty in the estimates because of the small sample size. Further research is needed to confirm the results, to investigate intramammary application hygiene, to objectively assess environmental hygiene, and to assess associations with milking equipment function. Moreover, in this study, prevalent instead of incident cases at the farm and cow levels were used. As such, a temporal pattern in support of a causeeffect relationship could not be established. Last, the questionnaire administration was by interview, and the individual asking the questions was not blinded with respect to the status of the herd. This approach might have introduced bias and increased the magnitude of the observed associations. Special training for questionnaire administration was not provided. Nevertheless, mainly multiple-choice questions asking for farm practices during a specific time with discrete answer categories were used, leaving little room for misclassification. Because the literature review that was used to develop the questionnaire revealed mainly anecdotal evidence of many different risk factors, the researchers did not know which of these risk factors would play a major role in the development of Prototheca mastitis on farm. Furthermore, a conscious effort was made to aim for neutral administration of questions during the interview.

\section{CONCLUSIONS}

Prototheca mastitis is an emerging disease that should be considered in the differential diagnosis of cases of mastitis that are nonresponsive to antibiotic treatment. Determination of mastitis-causing agents is necessary for effective therapy, timely culling decisions, and specific preventive interventions. A producer-veterinarian relationship should be established and treatment options discussed to avoid excessive, unsuccessful, and extra-label antibiotic use for mastitis. Prototheca spp. might act as an opportunistic pathogen and may be promoted by antibiotic-induced suppression of the natural udder flora.

\section{ACKNOWLEDGMENTS}

The authors greatly appreciate the effort of the producers that participated in the study, the veterinarians that identified their affected clients, and the veterinary technicians who helped in collecting the milk samples. The authors thank Karen Hand (Strategic Solutions Group, Puslinch, ON, Canada), who helped with the DHI data collection. This study was supported by funds from Ontario Ministry of Agriculture, Food and Rural Affairs (OMAFRA, Guelph, ON, Canada), Animal Health and Welfare Branch.

\section{REFERENCES}

Ahrholdt, J., and U. Roesler. 2011. Genotypische Differenzierung von Prototheca-Isolaten aus Milchproben mastitiskranker Rinder in Deutschland [Genotypical differentiation of Prototheca isolates of milk samples from mastitis-affected cattle in Germany]. Berl. Munch. Tierarztl. Wochenschr. 124:108-113.(German with English abstract).

Anderson, K. L., and R. L. Walker. 1988. Sources of Prototheca spp. in a dairy herd environment. J. Am. Vet. Med. Assoc. 193:553-556.

Aouay, A., F. Coppée, S. Cloet, P. Cuvelier, A. Belayew, P.-E. Lagneau, and C. Mullender. 2008. Molecular characterization of Prototheca strains isolated from bovine mastitis. J. Mycol. Med. 18:224-227. 
Baumgärtner, B. 1997. Vorkommen und Bekämpfung der Protothekenmastitis des Rindes im Einzugsgebiet des Staatlichen Veterinärund Lebensmitteluntersuchungsamtes Potsdam [Occurrence and control of bovine mastitis cuased by Prototheca in the region of the Veterinary Institute Potsdam]. Prakt. Tierarzt 78:406-414. (German with English abstract).

Blaschke-Hellmessen, R., and H. Schuster. 1984. Untersuchungen zur Überlebensfähigkeit von Prototheca zopfii und Prototheca wickerhamii unter verschiedenen Umweltbedingungen [Studies into survival of Prototheca zopfii and Prototheca wickerhamii under variable environmental conditions]. Mh. Vet. Med. 39:852-856. (German with English abstract).

Bueno, V. F. F., A. J. de Mesquita, R. B. S. Neves, M. A. de Souza, A. R. Ribeiro, E. S. Nicolau, and A. N. de Oliveira. 2006. Epidemiological and clinical aspects of the first outbreak of bovine mastitis caused by Prototheca zopfii in Goiás State, Brazil. Mycopathologia 161:141-145.

CanWest DHI. 2009. Progress Report Ontario. Accessed May 24, 2011. http://www.canwestdhi.com/publications.htm.

Corbellini, L. G., D. Driemeier, C. Cruz, M. M. Dias, and L. Ferreiro. 2001. Bovine mastitis due to Prototheca zopfii: Clinical, epidemiological and pathological aspects in a Brazilian dairy herd. Trop. Anim. Health Prod. 33:463-470.

Costa, E. O., P. A. Melville, A. R. Ribeiro, E. T. Watanabe, and M. C. F. F. Parolari. 1997. Epidemiologic study of environmental sources in a Prototheca zopfii outbreak of bovine mastitis. Mycopathologia 137:33-36.

Costa, E. O., A. R. Ribeiro, E. T. Watanabe, R. B. Pardo, J. B. Silva, and R. B. Sanches. 1996. An increased incidence of mastitis caused by Prototheca species and Nocardia species on a farm in São Paulo, Brazil. Vet. Res. Commun. 20:237-241.

Dion, W. M. 1982. Bovine mastitis due to Prototheca zopfii II. Can. Vet. J. 23:272-275.

Dubravka, M., L. Suvajdžić, I. Pušić, B. Vidić, and V. Đorđević-Milić. 2006. Outbreak of endemic form of protothecal mastitis on a dairy farm. Acta Vet. (Beogr.) 56:259-265.

Enders, F., and A. Weber. 1993. Untersuchung zum Vorkommen von Prototheken in Kotproben von Rindern [Investigation on the occurrence of Prototheca spp. in fecal samples of cattle]. Berl. Munch. Tierarztl. Wochenschr. 106:165-169. (German with English abstract).

Hodges, R. T., J. T. S. Holland, F. J. A. Neilson, and N. M. Wallace. 1985. Prototheca zopfii mastitis in a herd of dairy cows. N. Z. Vet. J. 33:108-111.

Hogan, H. S., R. N. González, R. J. Harmon, S. C. Nickerson, S. P. Oliver, J. W. Pankey, and K. L. Smith. 1999. Laboratory Handbook on Bovine Mastitis. National Mastitis Council (NMC), Verona, WI.

Ito, T., R. Kano, H. Sobukawa, J. Ogawa, Y. Honda, Y. Hosoi, H. Shibuya, T. Sato, A. Hasegawa, and H. Kamata. 2011. Experimental infection of bovine mammary gland with Prototheca zopfii genotype 1. J. Vet. Med. Sci. 73:117-119.

Jánosi, S., G. Szigeti, F. Rátz, T. Laukó, J. Kerényi, M. Tenk, F. Katona, A. Huszenicza, M. Kulcsár, and G. Huszenicza. 2001. Prototheca zopfii mastitis in dairy herds under continental climatic conditions. Vet. Q. 23:80-83.

Jordan, E. R., T. Hickerson, and M. Tomaszewski. 2003. Evaluation of the effects of cooling ponds on bacterial population in bulk tank milk samples. Pages 316-317 in Proc. 42nd Annu. Mtg., National Mastitis Council (NMC), Fort Worth, TX. NMC, Verona, WI.

Lagneau, P. E. 1996. First isolation of Prototheca zopfii in bovine mastitis in Belgium. J. Mycol. Med. 6:145-148.

Lass-Flörl, C., and A. Mayr. 2007. Human protothecosis. Clin. Microbiol. Rev. 20:230-242.

Marques, S., E. Silva, C. Kraft, J. Carvalheira, A. Videira, V. A. R. Huss, and G. Thompson. 2008. Bovine mastitis associated with Prototheca blaschkeae. J. Clin. Microbiol. 46:1941-1945.
Möller, A., U. Truyen, and U. Roesler. 2007. Prototheca zopfii genotype 2 - The causative agent of bovine protothecal mastitis? Vet. Microbiol. 120:370-374.

Murugaiyan, J., J. Ahrholdt, V. Kowbel, and U. Roesler. 2012. Establishment of a matrix-assisted laser desorption ionization time-offlight mass spectrometry database for rapid identification of infectious achlorophyllous green micro-algae of the genus Prototheca. Clin. Microbiol. Infect. 18:461-467. http://dx.doi.org/10.1111/ j.1469-0691.2011.03593.x.

Osumi, T., Y. Kishimoto, R. Kano, H. Maruyama, M. Onozaki, K. Makimura, T. Ito, K. Matsubara, and A. Hasegawa. 2008. Prototheca zopfii genotypes isolated from cow barns and bovine mastitis in Japan. Vet. Microbiol. 131:419-423.

Pore, R. S., and T. A. Shahan. 1988. Prototheca zopfii: Natural, transient, occurrence in pigs and rats. Mycopathologia 101:85-88.

Pore, R. S., T. A. Shahan, M. D. Pore, and R. Blauwiekel. 1987. Occurrence of Prototheca zopfii, a mastitis pathogen, in milk. Vet. Microbiol. 15:315-323.

Roesler, U., A. Moller, A. Hensel, D. Baumann, and U. Truyen. 2006. Diversity within the current algal species Prototheca zopfii: A proposal for two Prototheca zopfii genotypes and description of a novel species, Prototheca blaschkeae sp. nov. Int. J. Syst. Evol. Microbiol. 56:1419-1425.

Rösler, U., and A. Hensel. 2003. Sanierung eines Prototheca zopfiiinfizierten Milchviehbestandes [Eradication of Prototheca zopfii infection in a dairy cattle herd]. Dtsch. Tierarztl. Wochenschr. 110:374-377. (German with English abstract)

Roth, K. 2009. Ätiologische Bedeutung von Prototheca zopfii Genotyp 2 bei der Protothekenmastitis des Rindes. [Aetiological role of Prototheca zopfii genotype 2 in bovine Prototheca mastitis.] Doctoral Diss. Freie Universität Berlin, Berlin, Germany. (German with English abstract)

Satoh, K., K. Ooe, H. Nagayama, and K. Makimura. 2010. Prototheca cutis sp. nov., a newly discovered pathogen of protothecosis isolated from inflamed human skin. Int. J. Syst. Evol. Microbiol. 60:1236-1240.

Spalton, D. E. 1985. Bovine mastitis caused by Prototheca zopfii: A case study. Vet. Rec. 116:347-349.

Tenhagen, B.-A., A. Hille, A. Schmidt, and W. Heuwieser. 2005. Entwicklung von Zellgehalt und Ausscheidung von Prototheca spp. in der Milch infizierter Euterviertel von Kühen [Shedding patterns and somatic cell counts in milk from quarters chronically infected with Prototheca spp.]. Dtsch. Tierarztl. Wochenschr. 112:44-48. (German with English abstract).

Tenhagen, B.-A., P. Kalbe, G. Klünder, W. Heuwieser, and B. Baumgärtner. 1999. Tierindividuelle Risikofaktoren für die Protothekenmastitis des Rindes [Cow specific risk factors for mastitis caused by Prototheca spp.]. Dtsch. Tierarztl. Wochenschr. 106:376-380.(German with English abstract).

von Bergen, M., A. Eidner, F. Schmidt, J. Murugaiyan, H. Wirth, H. Binder, T. Maier, and U. Roesler. 2009. Identification of harmless and pathogenic algae of the genus Prototheca by MALDI-MS. Proteomics Clin. Appl. 3:774-784.

Wilson, D. J., R. N. Gonzalez, and H. H. Das. 1997. Bovine mastitis pathogens in New York and Pennsylvania: Prevalence and effects on somatic cell count and milk production. J. Dairy Sci. 80:2592-2598.

Zhang, Q., X. Weng, L. Li, L. Zhu, S. Yu, S. Chen, Y. Xiang, H. Wan, Y. Ran, and K. Kang. 2010. An unusual case of granulomatous lymphadenitis due to Prototheca zopfii var. portoricensis in an immunocompetent man in China. Int. J. Infect. Dis. 14(Suppl. 3):e32-e35. 